\title{
PLU-1/JARID1B/KDM5B is required for embryonic survival and contributes to cell proliferation in the mammary gland and in $\mathrm{ER}^{+}$breast cancer cells
}

\author{
STEVEN CATCHPOLE ${ }^{1}$, BRADLEY SPENCER-DENE ${ }^{2,3}$, DEBBIE HALL ${ }^{1}$, \\ SAMANTHA SANTANGELO ${ }^{1}$, IAN ROSEWELL ${ }^{4}$, MOUNIA GUENATRI ${ }^{5}$, RICHARD BEATSON ${ }^{1}$, \\ ANGELO G. SCIBETTA ${ }^{1,6}$, JOY M. BURCHELL ${ }^{1 *}$ and JOYCE TAYLOR-PAPADIMITRIOU ${ }^{1 *}$
}

\begin{abstract}
${ }^{1}$ Breast Cancer Biology, King's College London, Guy's Hospital, London SE1 9RT; ${ }^{2}$ Experimental Histopathology Laboratory, Cancer Research UK London Institute, 44 Lincoln's Inn Fields, London WC2A 3PX; ${ }^{3}$ Histopathology, Imperial College London, London, W12 ONN; ${ }^{4}$ Biological Resources, Cancer Research UK London Institute, Clare Hall Laboratories, South Mimms, Hertfordshire, UK; ${ }^{5}$ Institute Curie, UMR3215/Inserm U934, Paris, France
\end{abstract}

Received January 13, 2011; Accepted February 7, 2011

DOI: $10.3892 /$ ijo.2011.956

\begin{abstract}
The four members of the JARID1/KDM5 family of proteins, a sub-group of the larger ARID (AT rich DNA binding domain) family, have been shown to demethylate trimethylated lysine 4 on histone 3 (H3K4me3), a chromatin mark associated with actively transcribed genes. In some lower organisms a single homologue of JARID1 is found, and functions of the four proteins found in mice and humans may be specific or overlapping. To investigate the function of the JARID1B protein we examined the effects of deletion of the gene in mice. Systemic knock out of Jaridl $b$ resulted in early embryonic lethality, whereas mice not expressing the related Jarid1A gene are viable and fertile. A second mouse strain expressing a Jaridlb gene with the ARID domain deleted was viable and fertile but displayed a mammary phenotype, where terminal end bud development and side branching was delayed at puberty and in early pregnancy. Since development of terminal end buds are completely dependent on signalling from the
\end{abstract}

Correspondence to: Dr Joy Burchell or Dr Joyce TaylorPapadimitriou, Breast Cancer Biology, King's College London, Guy's Hospital, London SE1 9RT, UK

E-mail: joy.burchell@kcl.ac.uk

E-mail: joyce.taylor-papadimtriou@kcl.ac.uk

Present address: ${ }^{6}$ Centre for Tumour Biology, Bart's and The London School of Medicine \& Dentistry, John Vane Science Centre, Charterhouse Square, London, UK

${ }^{*}$ Contributed equally

Key words: histone demethylase, PLU-1, JARID1B, KDM5B, breast cancer, mouse knock-out, embryonic lethal, mammary gland development, estrogen receptor, $\mathrm{ER}^{+}$tumour growth estrogen receptor $(\mathrm{ER} \alpha)$, we investigated the expression of a target gene (progesterone receptor) in the $\triangle \mathrm{ARID}$ mouse and found levels to be reduced as compared to wild-type. JARID1B is widely expressed in $\mathrm{ER}^{+}$breast cancers and breast cancer cell lines, and interaction with $\mathrm{ER} \alpha$ was demonstrated by co-immunoprecipitations in cells transfected with tagged $E R \alpha$ and $J A R I D I B$ genes. Down-regulation of expression of JARID1B using shRNAi in MCF-7 cells resulted in a dramatic decrease in E2 stimulated tumour growth in nude mice. The data demonstrate a specific role for Jarid1B in early embryonic development, in the development and differentiation of the normal mammary gland, and in estrogen induced growth of $\mathrm{ER}^{+}$breast cancer.

\section{Introduction}

Dynamic changes in histone modifications such as acetylation, phosphorylation and methylation play a significant role in differentiation and development (1-3). In this context the JARID1/KDM5 group of histone demethylases [KDM5:lysine demethylase 5 (4)] have engendered considerable interest as the first identified proteins able, through the jumonji domain, to demethylate tri-methylated lysine 4 on histone 3 (5-9), a mark generally associated with promoters of actively transcribed genes (1). JARID1 homologues are represented by a single gene in lower organisms for example Lid in Drosophila $(10,14)$ and $r b r-2$ in C.elegans $(6)$, while 4 proteins are found in mammals. Although some redundancy might be expected, specific function could be generated by differing profiles of expression. SMXC/JARID1C/KDM5C, [a gene on the X chromosome which is not inactivated (16)], is expressed preferentially in neuronal tissue and is associated with neuronal survival and $X$ linked mental retardation $(7,13)$. The $\mathrm{RB}$ binding protein RBP2/JARID1A/KDM5A (14), is widely expressed $(3,6,8,15)$, and PLU-1/JARID1B/KDM5B [JARID1B nomenclature used throughout this report], shows a highly restricted expression in normal adult tissues, being largely 
confined to the testis and the differentiating mammary gland (16-18). JARID1B is however expressed in breast cancer $(16,18)$ being strongly associated with $\mathrm{ER}^{+}$cancers (19), and ectopic expression is also seen in cancers deriving from tissues normally not expressing the protein (20). In melanoma, JARID1B defines a subpopulation of slowly cycling cells necessary for continuous tumour growth (21).

Specificity of function may also depend on sequence differences. Although the four JARID1 proteins show high sequence homology, the conservation is less stringent at the 3 '-end that contains the LXCXE RB binding sequence found only in JARID1A $(14,16)$, and two PHD domains. One of these (PHD3) is absent in JARID1C and D and the second (PHD2), present in all four proteins shows sequence differences to JARID1B. PHD domains are involved in interactions with other proteins forming complexes, the composition of which depends on the cell context. Differences in complex formation might therefore be expected among the JARID1 proteins. Studies looking at protein interactions of the JARID1 demethylases have focused on their function in repression of transcription, relating this to the demethylation of $\mathrm{H} 3 \mathrm{~K} 4 \mathrm{me} 3$ at promoters of down-regulated genes $(3,5,22)$. JARID1B associates with HDACs through the PHD2 and PHD3 domains (17), while JARID1A associates with the Notch-RBP-J repressor complex through the PHD3 but not the PHD2 sequence (23). JARID1A and $\mathrm{B}$ have been reported to associate with different components of the repressive polycomb complexes $(24,25)$. Nevertheless, interactions with other transcription factors including myc and steroid receptors can result in activation of expression of target genes $(10,26,27)$.

Differences in tissue tropism are indicated from studies following effects of gene deletion. Thus deletion of Jaridla in the mouse results in defects in development of the hematopoietic system (8), however the homozygous $\mathrm{KO}$ is viable and fertile, as opposed to the $\mathrm{lid}^{-/-}$in the fly which is lethal (10). The knock out of the homologue of JARIDIC in the zebra fish results in defects in neuronal development and dendritic cell morphogenesis is impaired in rat (7). To investigate whether deletion of the $J a r i d l b$ gene in the mouse would indicate a role for the involvement of JARID1B in mammary gland function, we attempted to develop a Jarid $1 b^{-/-}$mouse. We found that systemic $\mathrm{KO}$ of Jaridlb results in early embryonic lethality, indicating a crucial role for JARID1B in early embryonic development that cannot be rescued by the other Jarid1 proteins. However, expression of a mutated gene with the ARID domain deleted that also causes loss of demethylase activity $(5,27)$, resulted in a mammary gland phenotype, showing a reduction in the number of end buds developing at puberty, and a delay in side branching. This phenotype suggested that an effect on ER $\alpha$ signalling was involved, since an ER $\alpha$ KO mammary gland shows complete inhibition of the development of end buds $(28,29)$. Interaction with ER $\alpha$ is of great of interest, not only for normal mammary gland development but because it could be involved in the proliferation of ER positive cancers, where JARID1B is expressed. JARID1A interacts with ER $\alpha$ (26) and JARID1B with the androgen receptor (27). We therefore analysed interaction of JARID1B with ER $\alpha$, investigated the effect of JARID1B expression on the growth of an $\mathrm{ER}^{+}$breast cancer cell line, and sought to demonstrate a role for JARID1B in ER signalling in the $\triangle$ ARID mouse.

\section{Materials and methods}

Ethics statement. All animal work was under carried out under UK Home Office Project Licence Numbers: PPL 70/5930 and PPL 70/6847, strictly adhering to Home Office guidelines. This study was approved by the King's College London Ethics Review Process Committee and Cancer Research UK Ethics Review Process on 30th October, 2008.

Animal experiments. For staged pregnancies, observation of vaginal plug was designated as day zero. To ensure accuracy of staged pregnancies, embryos were assessed for stage of embryonic development at the point of mammary gland harvest. To study the development of the nulliparous mammary gland the female mice were caged together from birth in order to synchronize the estrous cycle. For the collection of mammary gland tissue or embryos, females were culled by carbon dioxide inhalation.

Mammary gland whole mounts. The right-sided thoracic and inguinal mammary glands (3rd and 4th from the neck respectively) were dissected onto glass slides and fixed flat overnight at room temperature in Carnoy's fixative $75 \%$ ethanol, 25\% glacial acetic acid). The mammary glands were serially hydrated in decreasing concentrations of ethanol, stained overnight at room temperature in Carmine solution ( $0.5 \%$ carmine dye $\mathrm{w} / \mathrm{v}, 0.2 \%$ aluminum potassium sulfate) and then dehydrated in increasing concentrations of ethanol.

\section{Development and screening of transgenic mice}

a) Exon $1 \mathrm{KO}$ mouse. A Jaridlb targeting vector designed to replace exon 1 was generated by flanking the loxP-neomycinLoxP expression cassette with genomic sequence amplified from the sv129/ola murine strain. The 5' $2.4 \mathrm{~kb}$ homologous region (HR1) and the 3' $5.7 \mathrm{~kb}$ homologous region (HR2) comprised of intronic 1 and 2 sequences respectively. After injection of the construct into male C57bl/129/ola ES cells, screening of G418-selected $(200 \mu \mathrm{g} / \mathrm{ml})$ ES clones was performed by Southern hybridization using a PCR generated probe within the 3 ' homologous region. Two positive clones (1A4, strain 1 and 1A8, strain 2) carrying the integrated targeting vector were injected into either C57BL/6 blastocysts (1A8) or C57BL/6 embryos at the 8 cell stage (1A4) of development. Genotyping on DNA obtained from ear snips or from early embryos was performed by PCR to distinguish the WT allele (TGGATTGTAACTCTGTTCTCCCTAC and TTCTACTAG CAACGGCAACACCTAG) from the allele that had undergone homologous recombination(CATCTGTCAGACCCTTAGTAC GCTA and GCTACCGGTGGATGTGGAATGTGTG) (Fig. 2). For the detection of Jarid1b expression and identification of

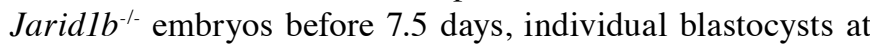
3.5 and $4.5 \mathrm{dpc}$ were genotyped by PCR after extraction of DNA with the Red extract-N-Amp tissue kit and amplification with the primers listed above.

b) The Jaridlb $\triangle A R I D$ mouse strain. A Jaridlb targeting vector was designed to replace exons 2-4. The targeting vector was generated by flanking the loxP-neomycin-LoxP expression cassette with genomic sequence amplified from the sv129/ola murine strain. The $5^{\prime} 7.3 \mathrm{~kb}$ homologous region (HR1) comprised of intron 2 and 48 bp of exon 2 and the 3 ' homologous region 
(HR2) comprised of $1.2 \mathrm{~kb}$ of intron 5 (Fig. 3). After injection of the construct into male 129/ola ES cells, screening of G418selected $(200 \mu \mathrm{g} / \mathrm{ml})$ ES clones was performed by Southern hybridization using a PCR generated probe $(1.2 \mathrm{~kb})$ within the 3 ' homologous region. A positive clone (2F9) carrying the integrated targeting vector was injected into C57BL/6 blastocyst to generate a single mouse lineage homozygous for the transgene. The C57BL/6/129ola chimeric strain was backcrossed over six generations onto the $\mathrm{C} 57 \mathrm{BL} / 6$ genetic background to give the JaridlB $\triangle$ ARID mouse strain.

Growth of tumours from MCF-7 cell clones in nude mice. Two clones of MCF-7 cells where JARID1B expression was constitutively knocked-down by shRNA (clones 4 and 29), and two lines from MCF-7 cells transfected with empty vector (clone 1 and pSUP mix) were studied (22). Balb/C Nu/Nu mice were implanted with estrogen implants (1.5 mg, 90-day release) $48 \mathrm{~h}$ before subcutaneously injecting the cells in matrigel. Appearance and size of tumours were monitored twice weekly. Statistical analysis was carried out using a two-tailed t-test.

End-point PCR. PCR amplification reactions were performed on $2 \mu \mathrm{l}$ of cDNA using AmpliTaq Gold (Applied Biosystems, Foster City, CA, USA) and primers specific to $P l u-1 /$ JaridlB exon 1 (5'-cgctttcatccacaagatcc-3') and exon 5 (5'-cagactg cctctggggaata-3'). PCR products were resolved on a $1.5 \%$ agarose gel, excised and purified using Wizard SV gel and PCR clean up systems (Promega, Madison, WI, USA) according to the manufacturer's instructions. DNA sequencing reactions were performed using BigDye terminator v3.1 cycle sequencing kit and 3730 DNA analyzer (Applied Biosystems).

Isolation of RNA and real-time PCR. Inguinal mammary glands (4th from the neck) and adult testis were collected, snap-frozen and total RNA isolated using the RNeasy Lipid tissue kit (Qiagen, Crawley, UK). Random hexamers were used to generate cDNA from $1 \mu \mathrm{g}$ of total RNA using Superscript III transcriptase (Invitrogen, Paisley, UK) according to the manufacturer's instructions. Relative quantification of target gene levels was achieved using SYBR Green JumpStart ReadyMix (Sigma-Aldrich, Poole, UK) according to the manufacturer's instructions and the Opticom 2 continuous florescence detector. Normalisation was against $18 \mathrm{~s}$ ribosomal RNA in separate tube reactions. To prevent amplification of genomic DNA PCR primers were designed to span intronic regions. The reactions were visualised by agarose gel electrophoresis to confirm target amplicon size. The $2^{-\Delta \Delta C T}$ method (Applied Biosystems; User Bulletin No. 2) was used to calculate the target gene expression level relative to the mammary gland identified as expressing the highest level of the target gene. Target gene and control gene amplification rates were comparable. Each group is represented as an average. Statistical analysis was carried out using a two-tail t test. Sense and anti-sense primer sequences are as follows: Jarid1b: 5'-CGA TAAACTTCATTTCACCCCG-3' and 5'-ACCCACCTTCTTC TGCGACTAAC-3'; 18s:5'-CTTCTTAGAGGGACAAGTGGC GTTCAG-3' and 5'-AACTGATCCTCCAAACCTCTTCTC-3'; Wnt4: 5'-GAGTGCCAATACCAGTTCCG-3' and 5'-CCAGCC TCGTTGTTG-3'; PR: 5'-CCCACAGGAGTTTGTCAAACT-3' and 5'-TCCGGGATTGGATGAATG-3'; ER $\alpha$ : 5'-CTAGCAGA
TAGGGAGCTGGTTCA-3' and 5'-GGAGATTCAAGTCCCC AAAGC-3'.

Cell culture. COS-7 cells were maintained in DMEM supplemented with $10 \%$ fetal calf serum and $0.3 \mu \mathrm{g} / \mathrm{ml}$ glutamine at $37^{\circ} \mathrm{C}$ in $10 \% \mathrm{CO}_{2} . \mathrm{MCF}-7$ cells were maintained in the same medium supplemented with $10 \mu \mathrm{g} / \mathrm{ml}$ insulin. Clones selected by shRNAi or with control vector were grown in $500 \mu \mathrm{g}$ of G418 (22).

Protein extraction and Western blot analysis. Inguinal mammary glands (4th from the neck) were collected, snap-frozen and nuclear protein extracts isolated using NE-PER nuclear and cytoplasmic extraction reagents (Pierce). Nuclear protein extract $(20 \mu \mathrm{g})$ was separated on a $6 \%$ polyacrylamide gel, as detailed previously (16).

Antibodies. The JARID1B antibody $\alpha$-PLU-1C, has been described previously $(17,18)$. Antibodies to Lamin B and HA were purchased from Santa Cruz Biotechnology (Calne, UK) and Covance (Princeton, NJ, USA) respectively. Antibody to the poly-Histidine tag was purchased from Sigma-Aldrich.

Plasmids. pcDNA3.1 Myc-His A PLU-1/JARID1B was described previously (16). pcDNA3.1 Myc-HisA PLU-1/ JARID1B $\triangle$ ARID was a kind gift from Dr C.D. Chen (27) and pXJ41neo-HA-ER was a gift from Dr W. Hong (26).

Transient transfections and immunoprecipitations. Cells were cultured to $50-80 \%$ confluence in $10-\mathrm{cm}$ plates for preparation of whole cell extracts and transfected using Lipofectamine LTX (Invitrogen, Paisley, UK) according to the manufacturer's instructions. Twenty-four hours post-transfection, cells were washed twice with PBS, then lysed for $15 \mathrm{~min}$ on ice in $50 \mathrm{mM}$ Tris (pH 8.0), $150 \mathrm{mM} \mathrm{NaCl}, 10 \%$ glycerol, $0.5 \%$ Triton $\mathrm{X}-100$, plus EDTA-free complete protease inhibitor cocktail (Roche, Lewes, UK). Cells were passed ten times on ice through a fine gauge needle, centrifuged to pellet cell debris and the supernatant pre-cleared with protein A/G agarose beads (Pierce). To $300 \mu \mathrm{g}$ of supernatant, $30 \mu \mathrm{l}$ of antibody conjugated agarose was incubated overnight at $4^{\circ} \mathrm{C}$.

In situ hybridization. In situ hybridization was carried out as previously described using actin as a positive control to ensure integrity of the blocks (18).

\section{Results}

Expression of Jaridlb in the mammary gland. We have previously shown that Jarid1b is expressed in the mammary bud in the mouse embryo and in the pregnant mammary gland in the adult mouse (18). Analysis of levels of expression of Jarid $1 b$ mRNA at different stages of differentiation in the mammary gland showed that expression is seen in the virgin gland, but the level is increased at pregnancy, decreased at lactation and re expressed to some degree at involution. Fig. 1A shows the profile of expression in C57BL/6 mice, but a similar pattern of expression is seen in Balb/C mice (30). To look at the expression at the cellular level, we used in situ hybridization $(16,18)$ looking at sections of the virgin mammary gland (4 and 
A

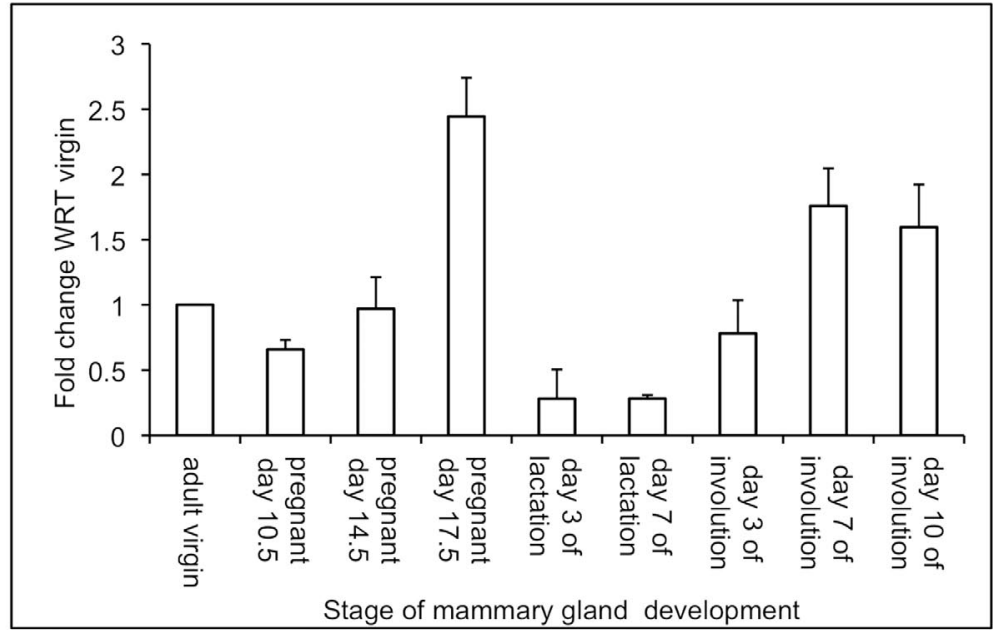

B
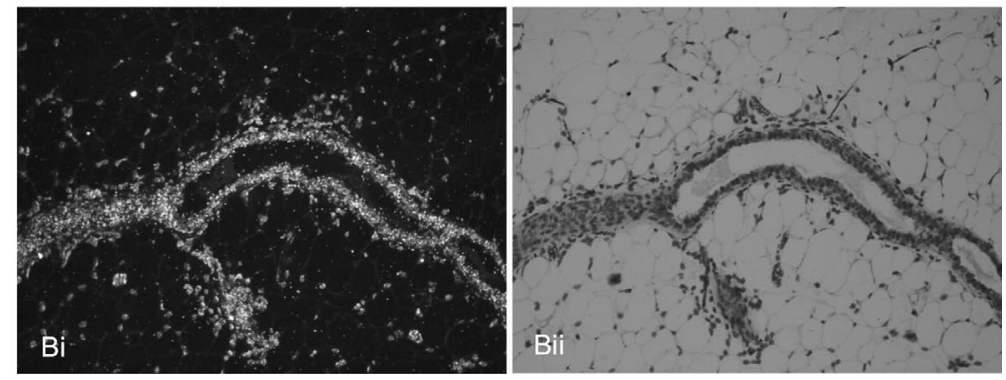

Figure 1. Expression of Jarid1b in the C57BL/6 murine mammary gland. (A) The expression of the Jarid1b transcript was determined by qRT-PCR and the level related to that expressed by the virgin mammary gland. (B) In situ hybridization showing that the Jarid1b transcript in mammary epithelial cells. Paired light field H\&E staining (Bii) and dark field (Bi) on a 12-week old (adult) C57BL/6 WT nulliparous mammary gland section showing ductal development with side branching and the localisation of the Jarid1b transcript to mammary gland epithelial cells.

Table I. Systemic knock out of Jaridlb is an early embryonic lethal.

A, Genotyping of progeny from a heterozygous Jaridlb/ExlKO breeding program

\begin{tabular}{lcccc}
\hline & Number of mice & Wild-type & Heterozygote & Homozygote KO \\
\hline Strain 1A4 (14 litters) & 139 & 67 & 72 & 0 \\
Strain 1A8 (18 litters) & 106 & 57 & 49 & 0 \\
\hline \multicolumn{2}{l}{ B, Genotyping of embryos from a heterozygous Jarid1b/Ex1 } & & \\
\hline Strain 1A4 & \multicolumn{2}{c}{ breeding program } & & Total \\
Wild-type & E9.5-10.5 & E8.0-8.5 & 0 & 6 \\
Heterozygote & 4 & 2 & 7 & $20^{\mathrm{a}}$ \\
Homozygote KO & 4 & 9 & 0 & 0 \\
Strain 1A8 & 0 & 0 & E7.5 & 3 \\
Wild-type & E9.5-10.5 & E8.0-8.5 & 1 & $23^{\mathrm{a}}$ \\
Heterozygote & 0 & 2 & 13 & 0 \\
Homozygote KO & 5 & 5 & 0 & 0 \\
\hline
\end{tabular}

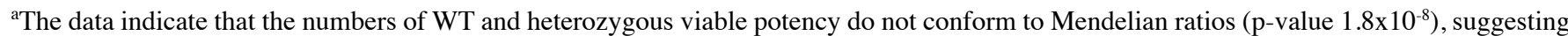
that some embryos heterozygous for Jaridlb may not survive in late pregnancy.

12 weeks) and in the pregnant gland (pd12 and pd18). The data show that Jaridlb is expressed in the luminal epithelial cells (see Fig. 1B for the 12-day virgin gland), indicating that any effects on regulation of gene expression will be seen in the epithelial compartment, where ER $\alpha$ is also expressed and functional (29).
Lack of expression of Jaridlb leads to embryonic lethality. To study the function of JARID1B in vivo, knock out mice were developed, using the strategy illustrated in Fig. 2. Recombination of the injected linearised construct in ES cells resulted in replacement of exon 1 with the neomycin gene. The selected ES cells (Fig. 2B) were injected into C57BL/6 blastocysts or 


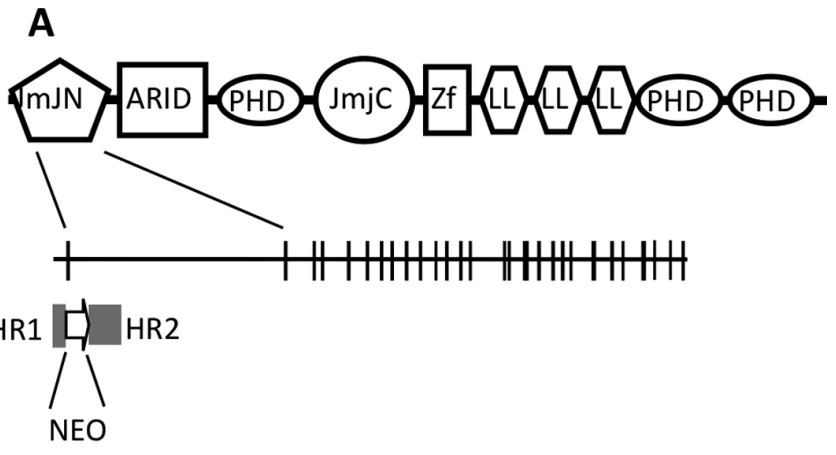

B

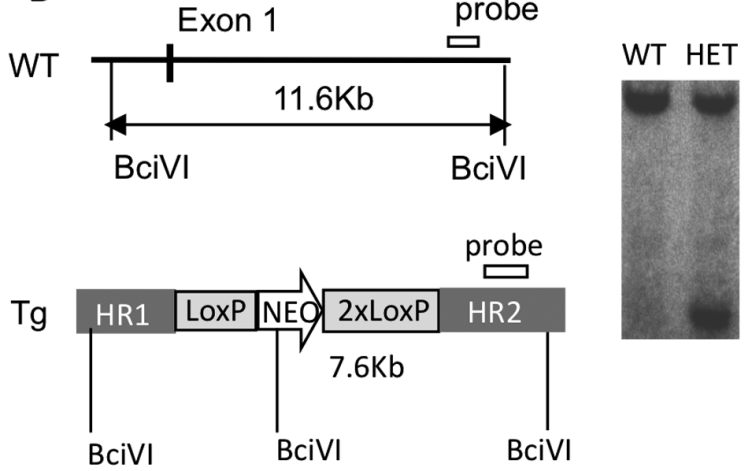

C
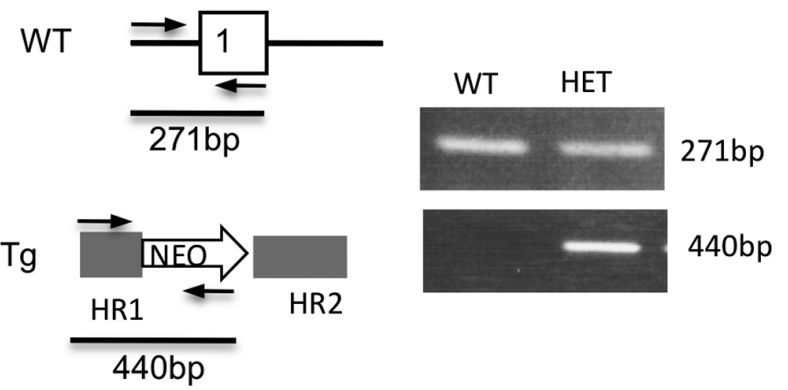

Figure 2. Generation of Jarid1b exon 1 construct and screening strategy used to detect homologous recombination. (A) Schematic representation of Jarid1b depicting protein domains, genomic organisation and the $5^{\prime} / 3^{\prime}$ homologous regions (HR1 and HR2). (B) Enlarged schematic depicting the WT and transgenic allele after homologous recombination and the location of the BciVI restriction sites used to distinguish the WT from the recombined allele. Southern blotting of a BciVI digest of C57bl/sv129 hybrid ES cell genomic DNA showing homologous recombination. (C) Schematic representation showing PCR primer location (arrows) used to screen DNA for homologous recombination (see Materials and methods).

8 cell embryos. Several males carrying the recombined gene were identified, and two strains (1A4 and 1A8) were developed from two of the founders. The recombined and wild-type genes were detected in DNA from ear snips using the PCR assays described in Materials and methods, and Fig. 2C shows the bands detected in WT and heterozygous mice using these assays.

Litters from crosses between heterozygotes were analysed for genotype in both mouse strains and no homozygote offspring were detected in a total of 139 from strain 1A4, and in a total of 106 from strain 1A8 (Table IA). Mice heterozygous for the defective gene were viable and fertile and showed no abnormalities of internal organs or abnormal behaviour and no obvious difference in mammary phenotype from the WT mice. Embryos from heterozygous crosses were also examined after timed matings, and no homozygous embryos were found for either strain at E7.5 (Table IB). Examination of earlier embryos from crosses between Jaridl ${ }^{+/-}$heterozygotes showed that Jaridlb $^{-/}$embryos could be identified up to E4.5, but attempts to develop Jarid1 $b^{-/}$ES cell lines have been unsuccessful. The results indicate that the defect induced by lack of expression of Jarid1b occurs early in embryonic development, before or just after implantation.

Development of the Jaridlb $\triangle A R I D$ mouse. Using a different approach to develop a mouse strain lacking expression of the Jarid1b protein, we replaced exons 2-4 with a floxed neomycin gene, which should have resulted in expression of a truncated mRNA with no translated sequences. Fig. 3 shows the strategy, the construct used, and the Southern blot of a Pst1 digest of the DNA from the injected ES cells showing homologous recombination.

A homozygous mouse strain expressing the modified Jaridb gene was developed on the C57BL/6/129 background, with both male and female mice being viable and fertile with pups born according to a Mendelian ratio. However, examination of the mRNA expressed in testis and in the pregnant mammary gland (tissues known to express high levels of Jaridlb), showed that exon 1 was spliced to exon 5, thus removing the neomycin gene. This is illustrated in Fig. 3C for RNA extracted from the mammary gland at day 18 of pregnancy, which shows the reduced size of the PCR product in the transgenic mouse using primers in exons 1 and 5. Exons 2-4 encode 5 amino acids of the JmjN domain and the entire ARID domain. Therefore, in frame splicing of the primary transcript from exons 1-5 results in the truncation of the JmjN domain (deletion of amino acids, Asp69, Trp70, Gln71, Pro72, Pro73) and complete deletion of the ARID domain. This mouse has therefore been termed the Jaridlb $\triangle$ ARID strain.

Examination of levels of Jaridlb RNA by RTqPCR in the 18.5 day pregnant mammary gland indicated an increase in the level in the Jarid1b $\triangle$ ARID mouse mammary gland (Fig. 3D), while levels of protein were reduced in comparison with the WT gland (Fig. 3E). The mice were viable and fertile showing no gross abnormalities in size, or differences in the morphology of internal organs and tissues, but the development of the mammary gland appeared to be affected. As this is difficult to quantitate on the mixed background, because of strain differences in profiles of development (31), for detailed examination of the morphology of the developing and differentiating mammary gland the mice were backcrossed on to a C57BL/6 background (6 backcrosses).

The Jaridlb $\triangle A R I D$ mammary gland presents with fewer terminal end buds and a defect in ductal elongation and side branching. To determine whether nulliparous mammary gland development was affected in the Jarid1b $\triangle$ ARID mouse, thoracic mammary glands at 4 and 12 weeks were whole mounted and stained with carmine (see Materials and methods). Fig. 4A shows that the Jarid1b $\triangle$ ARID nulliparous gland at 4 weeks of age presents with a less organised ductal system 


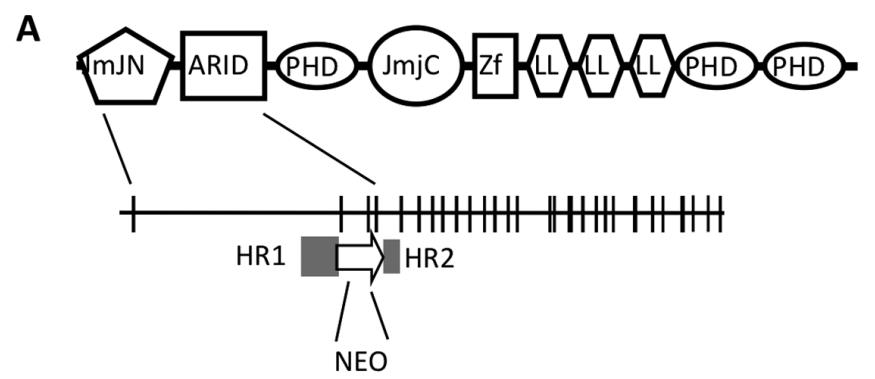

B

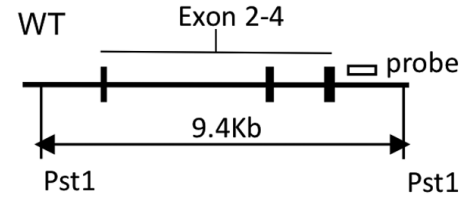

C

Exon 2-4 encode for part of the JmjN domain and the entire ARID domain

WT

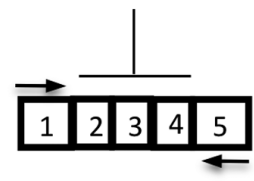

D

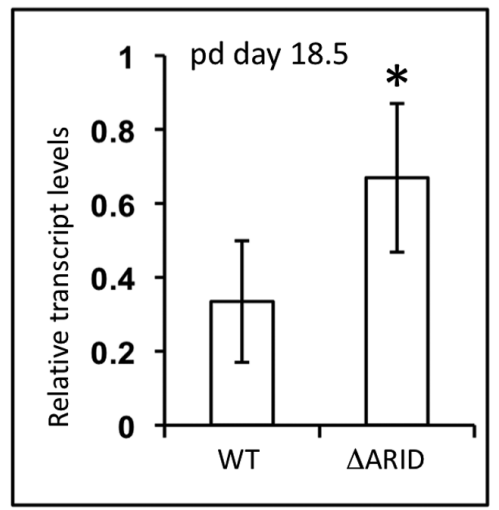

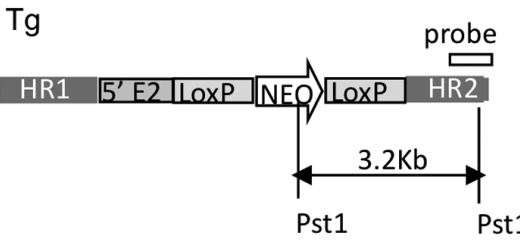

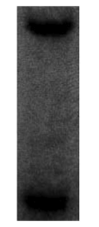

$9.4 \mathrm{~Kb}$

$3.2 \mathrm{~Kb}$
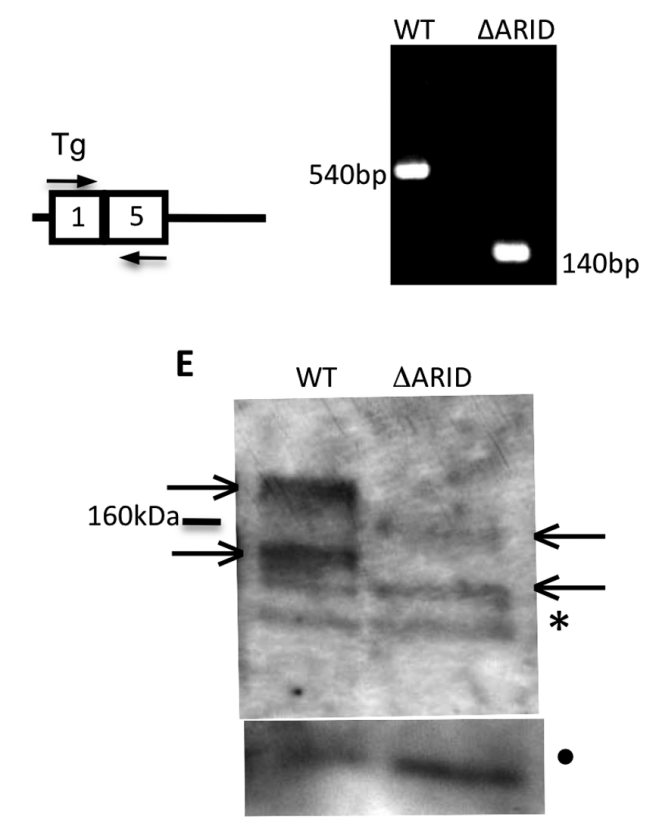

Figure 3. Generation of Jaridlb $\triangle$ ARID construct and screening strategy used to detect homologous recombination. (A) Schematic representation of Jaridlb depicting Jaridlb protein domains, genomic organisation and the 5'/3' homologous regions (HR1 and HR2). (B) Enlarged schematic depicting the WT and transgenic allele after homologous recombination and the location of the Pst1 restriction sites used to distinguish the WT from the recombined allele. Southern blottig shows homologous recombination using sv129 ES cell genomic DNA and PstI digest. (C) Schematic representation of the WT mRNA and after aberrant splicing from exon 1 to 5 removing the neomycin sequences, showing PCR primers (arrows); also RT-PCR using cDNA from the mammary gland at day 18.5 of pregnancy demonstrating exon 1-5 splicing (confirmed by sequencing the PCR product, data not shown). (D) Quantitative RT-PCR using primers downstream of the ARID domain showing an increase in Jaridlb $\triangle$ ARID transcript compared to WT at day 18.5 of pregnancy. $(\mathrm{P}<0.02$. WT, $\mathrm{n}=4$. $\triangle$ ARID, $n=5$ ). (E) Western blotting of Jarid1b in nuclear extracts from the mammary gland from mice at day 18.5 of pregnancy (arrows), "non-specific signal; 'Lamin B.

(Fig. 4Aii) than the wild-type gland (Fig. 4Ai), with on average 2.5 -fold reduction in TEB number (Fig. 4A top histogram $\mathrm{p}<0.0005)$. This effect was also seen in the inguinal gland (data not shown). By adulthood (12 weeks), as compared to the WT gland (Fig. 4Aiii), the mammary gland of the Jarid1b $\triangle$ ARID adult female (Fig. 4Aiv) had failed to fully ramify the fat pad, presented with fewer ductal bifurcation points (Fig. 4A bottom histogram $\mathrm{p}<0.005)$ and showed a distinct lack of secondary side branches trailing the primary ducts (Fig. 4Aiv). By 20 weeks of age the adult nulliparous mammary gland of the Jaridlb $\triangle$ ARID female had ramified the fat pad but still presented with fewer $\mathrm{Y}$ branch points and a lack of ductal side branches (data not shown).
Examination of the morphology of the Jaridlb $\triangle$ ARID mammary glands during pregnancy showed that a defect in side branching (resulting in the development of fewer alveoli) was still detectable at 12.5 days of pregnancy (compare Jaridlb $\triangle$ ARID Fig. 4Biii and iv with WT 4Bi and ii). However by day 18.5 of pregnancy, the gross morphology of the Jaridlb mammary glands was comparable to that of the WT glands (compare Jarid1b $\triangle$ ARID Fig. 4Bvii and and viii with WT $4 \mathrm{Bv}$ and vi), indicating recovery of the gland after the initial delay in development. Since the deletion of the ARID domain results in loss of demethylase activity of JARID1B, it is possible that this deficiency is responsible for the $\triangle$ ARID mammary gland phenotype particularly if the loss is only partial, allowing 
A
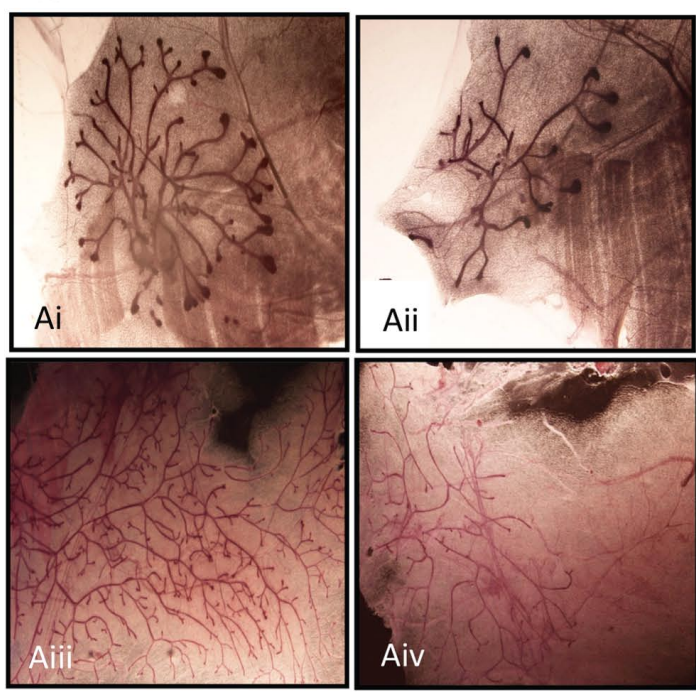
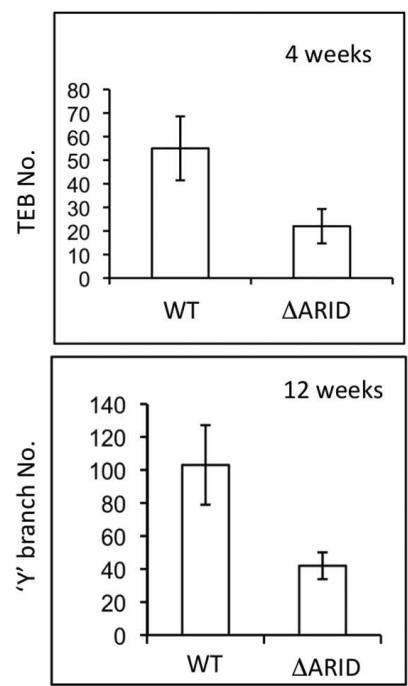

B

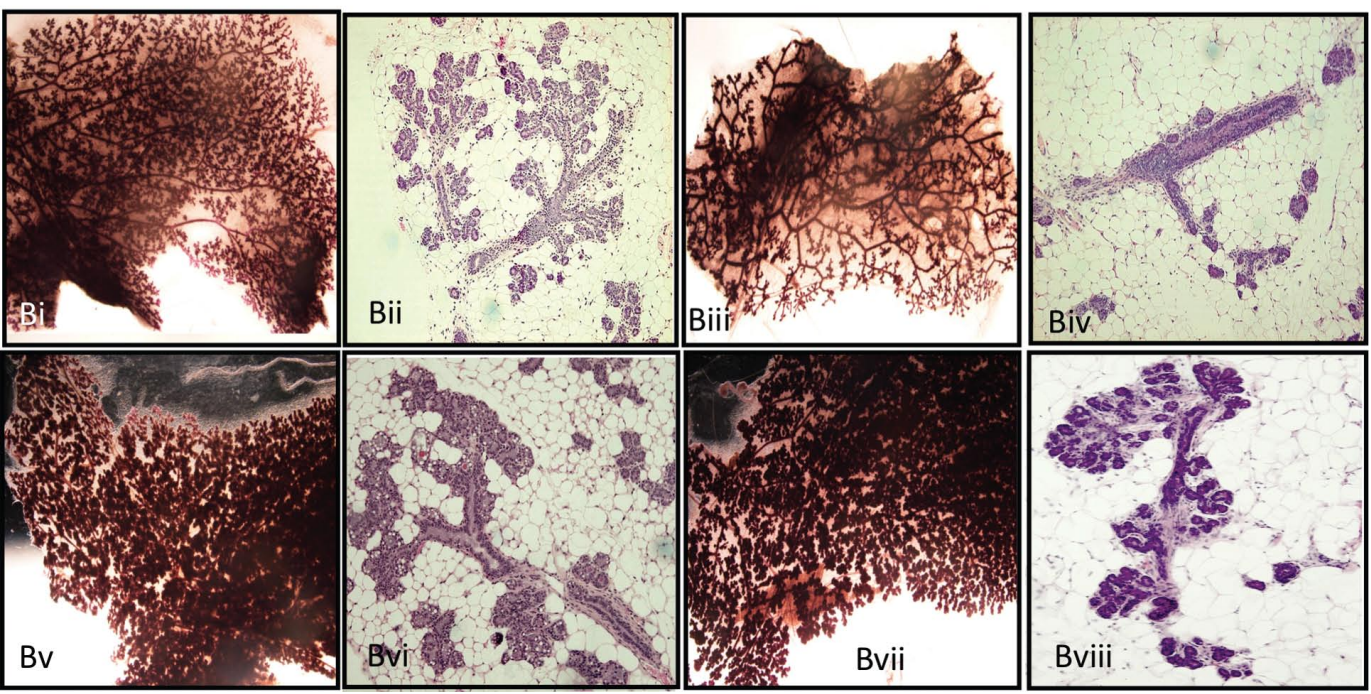

Figure 4. Abnormal mammary gland development in the C57BL/6 Jarid1b $\Delta$ ARID female mice. (A) Delayed development of the mammary tree in the pubertal gland. Representative carmine staining of thoracic mammary glands of C57BL/6 WT and C57BL/6 Jarid1b $\Delta$ ARID mice at 4 weeks (Ai and Aii respectively), and 12 weeks of age (Aiii and Aiv respectively). Quantification of the TEB number in the C57BL/6 nulliparous mammary glands at 4 weeks of age, (top histogram $n=6$ mice per group). Quantification of ' $\mathrm{Y}$ ' branch points (bifurcation) in the 12-week old adult mammary gland (bottom histogram WT, $\mathrm{n}=3$. $\Delta$ ARID, $\mathrm{n}=4$ ). (B) A delay in mammary gland development at mid-pregnancy is over come by late pregnancy. Representative carmine (i, iii, v and vii) and H\&E staining (ii, iv, vi and viii) of C57BL/6 WT (i, ii, v and vi) and C57BL/6 Jarid1b $\triangle$ ARID (iii, iv, vii, viii) thoracic mammary glands at day 12.5 (i-iv) and day 18.5 (v-viii) of pregnancy.

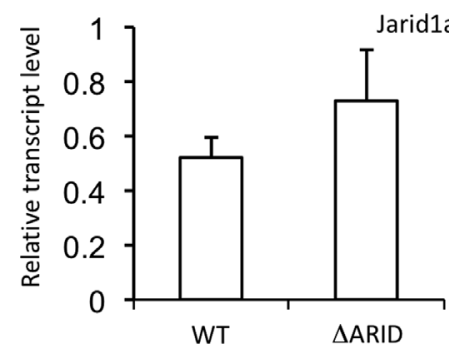

Figure 5. Levels of expression of Jarid1a are not significantly different in the $\triangle$ ARID mouse. Quantitative RT-PCR showing relative transcript levels (see Materials and methods) of Jarid1a in the mammary gland of C57BL/6 WT $(n=4)$ and Jarid1b $\triangle$ ARID $(n=4)$ mice at 18.5 days of pregnancy.

for recovery of the gland. The level of Jarid1a expression is not significantly increased $(\mathrm{p}=0.09)$ in $\triangle \mathrm{ARID}$ mammary glands as compared to the WT (Fig. 5), suggesting that compensation for reduced demethylase activity is not occurring.

Nulliparous mammary gland ductal development is crucially dependent upon epithelial ER $\alpha$ signalling: in the ER $\alpha$ knock out mammary gland at 4 weeks of age, terminal end buds (TEB) were absent and no further ductal elongation had occurred by adulthood $(28,29)$. Moreover, the $\triangle$ ARID mammary phenotype is remarkably similar to that seen in the $\mathrm{KO}$ of a co-regulator of the ER $\alpha$ receptor CITEDI (32). A possible explanation for the $\triangle$ ARID phenotype is that JARID1B interacts with the ER $\alpha$ signalling pathway, and the JARID1B $\triangle$ ARID protein is less functional in this interaction. We therefore looked at the levels of expression of the ER $\alpha$ itself and of a downstream target, the progesterone receptor (PR), using RT qPCR with RNA from the 12-week nulliparous gland. While the levels of ER $\alpha$ did not appear to be altered in the Jarid1b $\Delta$ ARID 
A

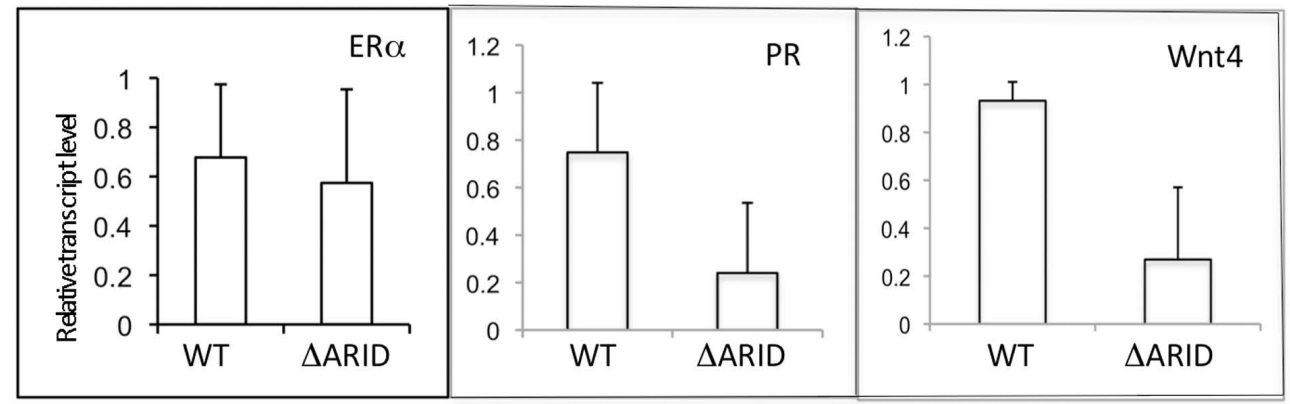

B

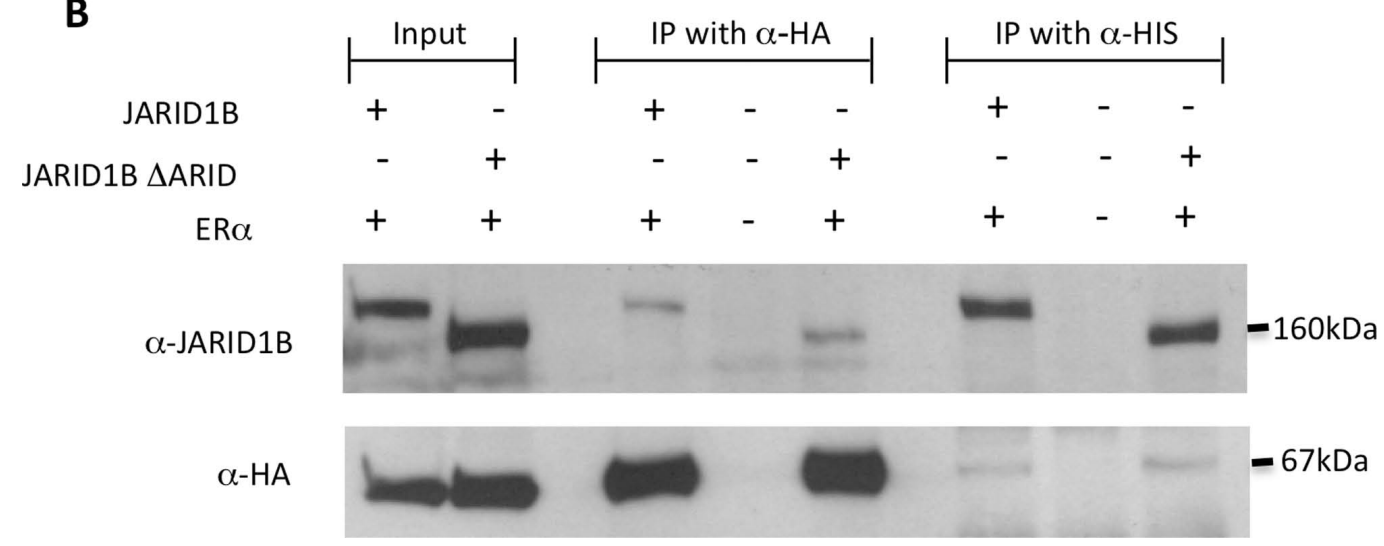

Figure 6. Jarid $1 \mathrm{~b}$ affects ER $\alpha$ signalling in the mammary gland and interacts with ER $\alpha$. (A) Quantitative RT-PCR showing relative transcript levels (see Materials and methods) of $E R \alpha, P R$, and Wnt4 in the nulliparous mammary glands from C57BL/6 WT and Jarid1b $\Delta$ ARID mice at 12 weeks of age (WT, n=3. $\Delta$ ARID, $\mathrm{n}=4$ ). One experiment representative of two is shown. (B) Myc His tagged JARID1B or $\triangle A R I D$ JARID1B and HA tagged ER $\alpha$, transiently expressed in COS-7 cells were immunoprecipitated with anti-HA or anti-His and subjected to Western blotting using anti-JARID1B antiserum (a-PLU-1C) or anti-HA antibody.

mammary gland, levels of PR mRNA were consistently lower in the Jarid1b $\triangle$ ARID gland, and almost reached significance $(p=0.074)$, even though a relatively small number of mice were available for analysis. Moreover, the levels of expression of Wnt4 mRNA, a downstream target of PR were significantly $(\mathrm{p}<0.02)$ lower in the Jarid1b $\triangle$ ARID mouse mammary gland (Fig. 6A).

JARIDIB interacts with ER $\alpha$. JARID1A has been shown to interact with $\mathrm{ER} \alpha$ (26) and JARID1B with the androgen receptor (27). As shown in Fig. 6B, we now find that JARID1B can interact with $\mathrm{ER} \alpha$ as demonstrated by co-precipitation of the two proteins in cells transfected with the tagged genes. Interestingly, interaction with $\mathrm{ER} \alpha$ also occurs with the JARID1B $\triangle$ ARID construct from Xiang et al (27). Since the $\triangle$ ARID JARID1B protein binds to ER $\alpha$, any impact of deleting the $\triangle \mathrm{ARID}$ domain would have to be on the function of the interacting complex. The reduced level of expression of the defective JARID1B protein (Fig. 3E) is unlikely to be responsible for the effect on mammary gland development, as the glands of the heterozygote mice from the embryonic lethal strain, where reduced levels of JARID1B are expressed, develop normally (data not shown).

Effect of depletion of JARIDIB expression on estrogen-dependent growth of MCF-7 cells grown as tumours in nude mice. JARID1B is preferentially expressed in $\mathrm{ER}^{+}$breast cancers and breast cancer cell lines $(16,17,19)$. To see if JARID1B is involved in ER $\alpha$ stimulated growth of $\mathrm{ER}^{+}$cells, we used shRNAi to look at the effect of knocking down expression of wild-type JARID1B on the growth of MCF-7 cells (22) grown as tumours in nude mice. Two MCF-7 lines, where expression of JARID1B was inhibited by shRNA knock-down (clones 4 and 29) and two lines transfected only with empty vector (pSUP mix and clone 1) were used for these experiments.

MCF-7 cells do not form tumours in nude mice without estrogen stimulation, and for analysis of estrogen-dependent growth of the cell lines in vivo, estrogen pellets were implanted into the mice $48 \mathrm{~h}$ before subcutaneous injection of cells in matrigel. Fig. 7Al shows the growth of shRNA knock-down clone 4 compared to two lines transfected with only the vector (pSUP 1 and pSUP mix) injected at $1 \times 10^{7}$ cells. Fig. 7All and Alll representing two different experiments, showing the growth of two RNAi clones and control clone pSUP 1 injected at a cell number of $1 \times 10^{6}$. Clearly the rate of tumour growth is dramatically faster when JARID1B is expressed with both cell concentrations (Fig. 7Al) shRNAi clone 4 against pSUP 1 and pSUP mix $p<0.005$ and $p<0.02$ respectively; Fig. 7All and Alll, pSUP1 against RNAi clone 4 and clone 29 p $<0.005$ and $\mathrm{p}<0.002$ respectively).

\section{Discussion}

Our studies seeking to understand the function of JARID1B using a mouse model and human cell lines have shown that expression of the protein is required for embryonic survival 
A
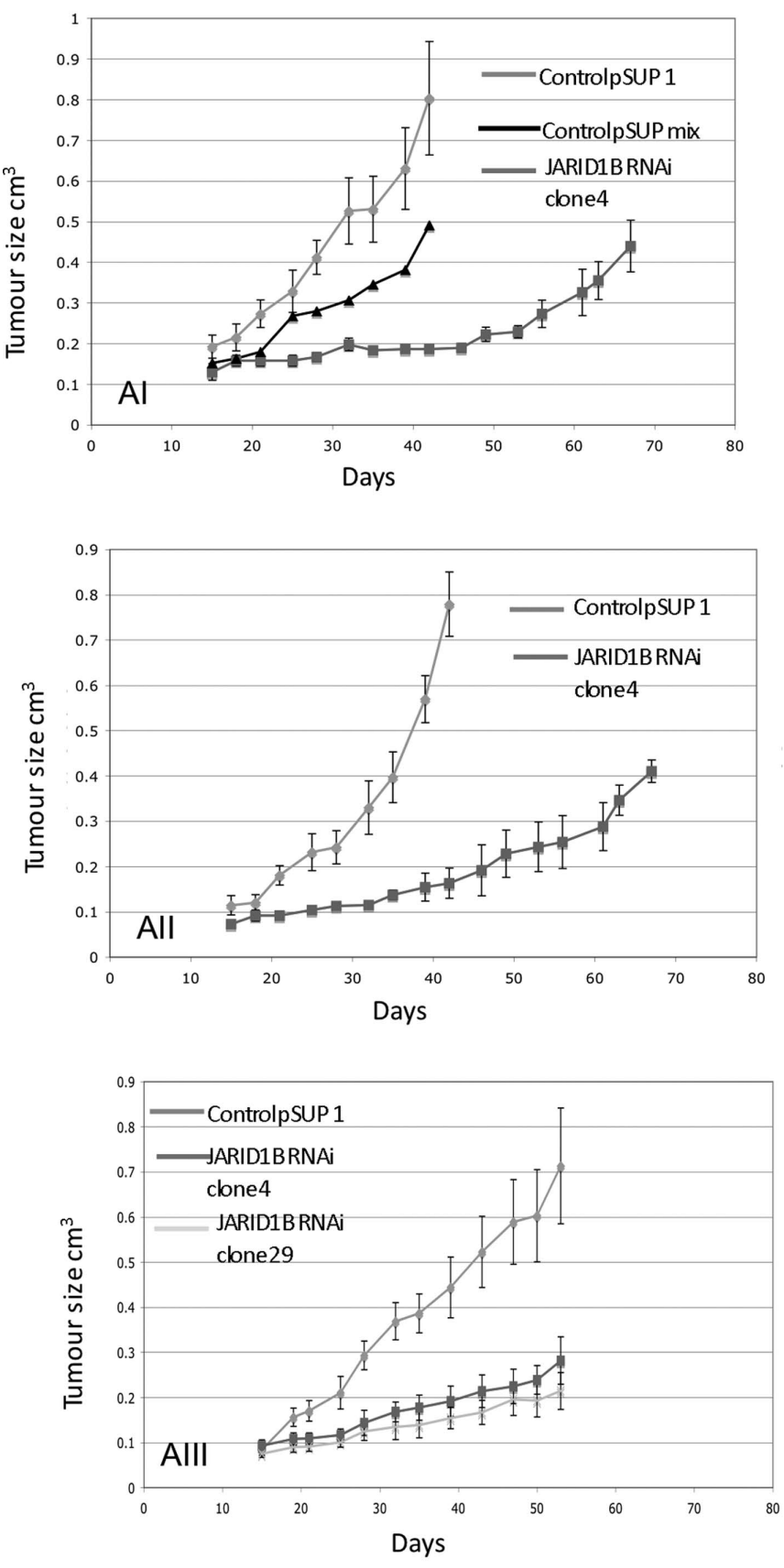

B

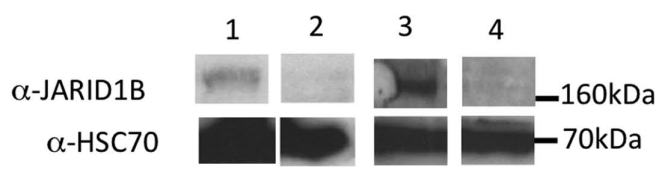

Figure 7. JARID1B enhances E2 dependent tumour growth of MCF-7 cells. (A) MCF-7 cells lines transfected with vector alone [control pSUP1, control pSUP mix) or with JARID1B shRNA (RNAi clone 4, RNAi clone 29 (22)] were subcutaneously injected, in matrigel, into nude mice pre-treated with estrogen pellets. (Al) Indicated cells were inoculated at a cell number of $1 \times 10^{7}$. (All and Alll) The results of two independent experiments are shown with mice injected with $1 \times 10^{6}$ cells. (B) Western blotting with anti-JARID1B (a-PLU-1 C) of: 1, control pSUP mix; 2, JARID1B knock-down clone 4; 3 , control pSUP1; 4, JARID1B knock-down clone 29.

and that in the mammary gland, and in breast cancer this nuclear protein can affect cell growth and ER $\alpha$ signalling.
Analysis of the offspring and embryos in the systemic knock out in the mouse showed that no Jarid $1 b^{-/}$offspring or E7.5 embryos were produced and Jaridl $b^{-/}$embryo development was arrested after E4.5, highlighting the requirement of Jaridlb for implantation and/or developmental stages immediately following implantation. The embryonic lethality is in contrast to the result of knocking out the close family member Jaridla, where mice are viable and fertile but later show defects in the hematopoietic system (8). Clearly Jarid1a or the other two Jarid1 proteins cannot compensate for loss of expression of Jarid1b in embryonic development. Deletion of expression of Jarid1 in lower organisms, where a single gene is operative, can be lethal as with the Drosphila Lid (10), while in C. elegans effects on vulva development are seen (6). Interestingly, deletion of another H3K4 demethylase Lsd1, which can demethylate $\mathrm{H} 3 \mathrm{~K} 4 \mathrm{me} 2$, also results in embryonic lethality in the mouse. Development was arrested at the same time as seen with the

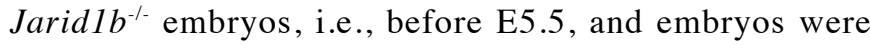
reabsorbed by 7.5 days $(33,34)$. The data agree with the observation that Jaridlb is strongly expressed in the epiblast of normal E5.5 embryos where uncommitted cells choose between proliferation and differentiation (35). Moreover, the fact that attempts to develop Jarid1b ${ }^{-/}$ES cells have been unsuccessful correlates with studies showing that mouse embryo ES cells do not survive upon abolishing Jarid1b expression by shRNA (36).

The viability of the Jaridlb $\triangle$ ARID mouse strain is somewhat surprising since deletion of the ARID domain is reported to result in loss of demethylase activity $(5,27)$. However, the assessment using immunofluorescence to detect changes in $\mathrm{H} 3 \mathrm{~K} 4 \mathrm{me} 3$ in cells transfected with the mutant cDNA is not quantitative and a small level of residual activity may be present. If Jarid1b demethylase activity is required for embryonic survival past E4.5, this must be specific to Jarid1b as the other members of the family do not compensate in the systemic $\mathrm{KO}$ embryos. This specific requirement is likely to depend on another function-specific to Jarid1b, involving the 3' sequences, where the main differences in sequence with the other JARID1 proteins are seen (16), and on which protein interactions involved in recruitment to specific chromatin domains may depend.

We have previously shown that Jarid1b is expressed in spermatagonia and at specific stages of meiosis (pachytene and diplotene) in the testis (37). However, both male and female Jarid1b $\triangle \mathrm{ARID}^{-/-}$mice are fertile. Again either the demethylase function of Jarid1b is not required for the development of the male gametes, or a residual activity is present, or activity can be assumed by another H3K4me3 demethylase. Jarid1d (38) is also expressed in the same stages of meiosis as Jarid1b, but not in spermatagonia (39). In C. elegans, the loss of function of the homologue (spr5) of the LSDI demethylase leads to the development of sterility over many generations (40). We observed no such effect over 10 generations in the $\triangle \mathrm{ARID}$ mouse.

The studies in the Jaridlb $\Delta$ ARID adult mouse are consistent with the hypothesis that Jarid1B plays a role in the development of the normal mammary gland at a stage where signalling from the ER $\alpha$ receptor is vital for expansion of the mammary tree. The ER $\alpha$ knock out mammary gland shows only a rudimentary ductal system, which does not progress (28) even 
when ER $\alpha$ expression is specifically ablated in the mammary epithelial cells (29). The Jarid1b $\triangle$ ARID mouse shows a delay in the development of the gland at puberty and early pregnancy, and the obvious reduction in end bud development at 4 weeks suggested that signalling from the ER $\alpha$ receptor might involve an interaction with JARID1B that is impaired in the JARID1B $\triangle$ ARID mammary glands. The reduced levels of the downstream target PR and its downstream target Wnt $4(41,42)$ support this idea. It is also interesting to note that a very similar mammary phenotype is seen in a mouse where the expression of the ER $\alpha$ co-regulator CITED1 has been ablated (32). As previously shown for the JARID1A protein (26) we found that an interaction of JARIDlb with ER $\alpha$ could be detected by co-precipitation. Interestingly, interaction was also seen with the JARID1B $\triangle$ ARID construct supporting the idea that deletion of the ARID domain affects the downstream function.

A highly significant association of JARID1B with $\mathrm{ER}^{+}$ cancers is found on analysing microarray data available in the public database (19), and expression of JARID1B is high in $\mathrm{ER}^{+}$cell lines $(16,43)$. Clearly interaction of JARID1B with $\mathrm{ER} \alpha$ could have profound effect on the growth of $\mathrm{ER}^{+}$cells. That this is indeed the case was demonstrated by finding a pronounced reduction in E2-dependent tumour growth of the $\mathrm{ER}^{+} \mathrm{MCF}-7$ breast cancer cell line when JARID1B expression was silenced by shRNAi.

The function of H3K4 demethylases as activators of transcription is dependent on interactions with specific transcription factors. It has been shown that LSD1, when interacting with $\mathrm{AR}$, can also demethylate $\mathrm{H} 3 \mathrm{~K} 9 \mathrm{me} 3$, which is normally a repressive mark (44), and this dependence on interacting proteins for substrate specificity could be a general phenomenon. Interaction of the $\mathrm{JmjC}$ domain with dmyc in Drosophila inactivates the demethylase activity and Lid then becomes involved in activation of myc targeted genes (10). Clearly, the composition of the complexes recruited is crucial to determining the function of the JARID1 proteins and other demethylases (45). JARID1A is a component of the MRG15 complex, when it is involved in activation of transcription, and it is proposed that JARID1A functions to maintain reduced H3K4 methylation ensuring the transcriptional elongation rate (46). Many complexes contain both methylases and demethylases together with components that may be cell specific. JARID1B is found in a complex purified form MCF-7 cells which also contains the H3K9 and H327 methylases G9a and EZH2, and the LSD1 demethylase (47). The formation of a specific complex can also depend on external signals, as with estrogen stimulation of cell growth, making it important to work within the appropriate cell $\left(\mathrm{ER}^{+}\right)$and growth environment.

Taken together, our data indicate that JARID1B function is crucial for embryonic development after E4.5, contributes to the differentiation orientated proliferation seen in the normal mammary gland, and to the proliferation of $\mathrm{ER}^{+}$breast cancer cells. Clearly it will now be important to identify on a global scale, genes which are regulated by ER $\alpha$ and which also require the involvement of JARID1B, and to define complex(es) containing both components. Investigation of the effect of JARID1B expression on the H3K4/H3K9/H327 methylation status of chromatin in different mammary phenotypes, could contribute to the definition of the epigenetic profile of stem and progenitor cells (21). It will also be important to characterise the novel function of JARID1B that is required for embryonic development after E4.5, and for survival in cultured ES cells.

\section{Acknowledgements}

The authors are extremely grateful to Janet McDonald at Cancer Research UK (CR UK) for the care and breeding of the transgenic mice, to Professor Richard Poulsom (CR UK) for the in situ hybridization studies, to Dr C.D. Chen and Dr W. Hong for plasmids, and to Fabrizio Miranda for assembling some of the data from the MCF-7 tumour experiments. This work was supported by KCL (fellowship to S.C.), a Cancer Research UK Programme grant to J.T.-P. and Breast Cancer Campaign grants to J.T.-P. and J.B. The authors also acknowledge financial support from the Department of Health via the National Institute for Health Research (NIHR) comprehensive Biomedical Research Centre award to Guy's \& St Thomas' NHS Foundation Trust in partnership with King's College London and King's College Hospital NHS Foundation Trust.

\section{References}

1. Berger SL: The complex language of chromatin regulation during transcription. Nature 447: 407-412, 2007.

2. Benevolenskaya EV: Histone H3K4 demethylases are essential in development and differentiation. Biochem Cell Biol 85: 435-443, 2007.

3. Cloos PAC, Christensen J, Agge RK and Helin K: Erasing the methyl mark: histone demethylases at the center of cellular differentiation and disease. Genes Dev 2: 1115-1140, 2008.

4. Allis CD, Berger SL, Cote J, et al: New nomenclature for chromatin-modifying enzymes. Cell 131: 633-636, 2007.

5. Yamane K, Klose RJ, Fabrizio LA, Erdjument-Bromage H, Taylor-Papadimitriou J, Tempst P and Zhanh Y: PLU-1 is an $\mathrm{H} 3 \mathrm{~K} 4$ demethylase involved in transcriptional repression and breast cancer cell proliferation. Mol Cell 25: 801-812, 2007.

6. Christensen J, Agger K, Cloos PA, et al: RBP2 belongs to a family of demethylases, specific for tri-and dimethylated lysine 4 on histone 3. Cell 28: 1063-1076, 2007.

7. Iwase S, Lan F, Bayliss P, et al: The X-linked mental retardation gene SMCX/JARID1C defines a family of histone H3 lysine 4 demethylases. Cell 128: 1077-1088, 2007.

8. Klose RJ, Yan Q, Tothova Z, et al: The retinoblastoma binding protein RBP2 is an H3K4 demethylase. Cell 128: 889-900, 2007.

9. Seward DJ, Cubberley G, Kim S, Schonewald M, Zhang L, Tripet B and Bentley DL: Demethylation of trimethylated histone H3 Lys4 in vivo by JARID1 JmjC proteins. Nat Struct Mol Biol 14: 240-242, 2007.

10. Secombe J, Li L, Carlos L and Eisenman RN: The Trithorax group protein Lid is a trimethyl histone $\mathrm{H} 3 \mathrm{~K} 4$ demethylase required for dMyc-induced cell growth. Genes Dev 21: 537-551, 2007.

11. Lee N, Zhang J, Klose RJ, Erdjument-Bromage, H, Tempst P, Jones RS and Zhang Y: The trithorax-group protein Lid is a histone H3 trimethyl-Lys4 demthylase. Nat Struct Mol Biol 14: 341-343, 2007.

12. Agulnik AJ, Mitchell MJ, Mattei MG, Borsani G and Avner PA: A novel $\mathrm{X}$ gene with a widely transcribed Y-linked homologue escapes X-inactivation in mouse and human. Hum Mol Genet 3: 879-884, 1994.

13. Jensen LR, Amende M, Gurok U, Moser B and Gimmel V: Mutations in the JARID1C gene which is involved in transcriptional regulation and chromatin remodelling cause X-linked mental retardation. Am J Hum Genet 76: 227-236, 2005.

14. Defoe Jones D, Huang PS, Jones RE, Haskell KM, Vuocolo GA, et al: Cloning of cDNAs for cellular proteins that bind to the retinoblastoma gene product. Nature 352: 251-254, 1991.

15. Lopez-Bigas N, Kisiel TA, De Waal DC, et al: Genome wide analysis of the $\mathrm{H} 3 \mathrm{~K} 4$ histone demethylase RBP2 reveals a transcriptional program controlling differentiation. Cell 31: 520-530, 2008. 
16. Lu PJ, Sundquist K, Baeckstrom D, et al: A novel gene (PLU-1) containing highly conserved putative DNA/chromatin binding motifs is specifically upregulated in breast cancer. J Biol Chem 274: 15633-15645, 1999.

17. Barrett A, Santangelo S, Tan K, et al: The breast cancer associated transcriptional repressor PLU1/JARID1B interacts directly with histone deacetylases. Int J Cancer 121: 265-275, 2007.

18. Madsen B, Spencer-Dene B, Poulsom R, et al: Characterisation and developmental expression of mouse Plu-1, a homologue of a human nuclear protein (PLU-1) which specifically upregulated in breast cancer. Mech Dev 119 (Suppl. 1): S239-S246, 2002.

19. Oncomine website www.oncomine.org

20. Hayami S, Yoshimatsu M, Veerakumarasivam A, et al: Overexpression of the JmjC demethylase KDM5B in human carcinogenesis; involvement in the proliferation of cancer cells through the E2F/ RB pathway. Mol Cancer 9: 59, 2010.

21. Roesch A, Fukunaga-Kalabis M, Schmidt EC, et al: A temporarily distinct subpolulation of slow-cycling melanoma cells is required for continuous tumour growth. Cell 141: 583-594, 2010.

22. Scibetta A, Santangelo S, Coleman J, et al: Functional analysis of the transcriptional repressor PLU-1/JARID1B. Mol Cell Bio 27: 7220-7235, 2007.

23. Liefke R, Oswald F, Alvarado C, et al: Histone demethylase KDM5A is an integral part of the core Notch-RB P-J repressor complex. Genes Dev 24: 590-601, 2010.

24. Zhou W, Chen H and Zhang L: The PcG protein hPc2 interacts with the $\mathrm{N}$ terminus of histone demethylase JARID1B and acts as a transcriptional co-repressor. BMB Rep 42: 154-159, 2008.

25. Pasini D, Hansen KH, Christensen J, Agger K, Cloos PAC and Helin K: Co-ordinated regulation of transcriptional repression by the RPB2 H3K4 demethylase and Polycomb repressive complex 2. Genes Dev 22: 1345-1355, 2008.

26. Chan SW and Hong W: Retinoblastoma-binding protein 2 (RBP2) potentiates nuclear receptor-mediated transcription. J Biol Chem 276: 28402-28412, 2002.

27. Xiang Y, Zhu Z, Han G, et al: JARID1B is a histone H3 lysine 4 demethylase up-regulated in prostate cancer. Proc Natl Acad Sci USA 104: 19226-19231, 2007.

28. Mallepel S, Krust A, Chambon P and Briskin C: Paracrine signalling through the epithelial estrogen receptora is required for proliferation and morphogenesis in the mammary gland. Proc Natl Acad Sci USA 103: 2196-2201, 2006.

29. Feng Y, Manka D, Wagner K-U and Khan SA: Estrogen receptor- $\alpha$ expression in the mammary epithelium is required for ductal and alveolar morphogenesis in mice. Proc Natl Acad Sci USA: 14718-14723, 2007.

30. Stein T, Morris JS, Davies CR, et al: Involution of the mouse mammary gland is associated with an immune cascade and an acute-phase response, involving LBP, CD14 and STAT3. Breast Cancer Res 6: 75-91, 2004.

31. Naylor MJ and Ormondy CJ: Mouse strain-specific patterns of mammary epithelial ductal side branching are elicited by stromal factors. Dev Dynam 225: 100-105, 2002.

32. Howlin J, McBryan J, Napoletano S, Lambe T, McArdle E, Shioda T and Martin F: CITED1 homozygous null mice display aberrant pubertal mammary ductal morphogenesis. Oncogene 25: 1532-1542, 2006.
33. Wang J Scully K, Zhu X, et al: Opposing LSD1 complexes function in developmental gene activation and repression programmes. Nature 446: 882-887, 2007.

34. Wang J, Hevi S, Kurash JK, et al: The lysine demthylase LSD1 (KDM1) is required for maintenance of global DNA methylation. Nat Genet 41: 125-1290, 2009.

35. Frankenberg S, Smith L, Greenfield A and Zernicka-Goetz M: Novel gene expression patterns along the proximo-distal axis of the mouse embryo before gastrulation. BMC Dev Biol 7: 1-13, 2007.

36. Dey BK, Stalker L, Schnerch A, Bhatia M, Taylor-Papadimitriou J and Wynder C: The histone demethylase KDM5b/JARID1b plays a role in cell fate decisions by blocking terminal differentiation. Mol Cell Biol 28: 5312-5327, 2008.

37. Madsen B, Tarsounas M, Burchell JM, Hall D, Poulsom R and Taylor-Papadimitriou J: PLU-1, a transcriptional repressor and putative testis-cancer antigen, has a specific expression and localization pattern during meiosis. Chromosoma 112: 124-132, 2003.

38. Agulnik AI, Longepied G, Ty MT, Bishop CE and Mitchell M: Mouse H-Y encoding Smcy gene and its $\mathrm{X}$ chromosomal homolog Smcx. Mamm Genome 10: 926-929, 1999.

39. Akimoto C, Kitagawa H, Matsumoto T and Kato S: Spermatogenesis-specific association of SMCY and MSH5. Genes Cells 13: 623-633, 2008.

40. Katz DJ, Edwards TM, Reinke V and Kelly WG: A C: C elegans LSD1 demethylase contributes to germline immortality by reprogramming epigenetic memory. Cell 137: 308-320, 2009.

41. Robinson GW, Hennighausen L and Johnson PF: Side-branching in the mammary gland: the progesterone-Wnt connection. Genes Dev 14: 889-894, 2000.

42. Brisken C, Heineman A, Chavarria T, Elenbaas and Tan J: Essential function of Wnt-4 in mammary gland development downstream of progesterone signalling. Genes Dev 14: 650-654, 2007.

43. Barrett A, Madsen B, Copier J, et al: The PLU-1 nuclear protein, which is upregulated in breast cancer, shows restricted expression in normal human adult tissues. Int J Cancer 101: 581-586, 2002.

44. Metzger E, Wissmann M, Yin N, et al: LSD1 demethylases repressive histone marks to promote androgen receptor dependent transcription. Nature 437: 436-439, 2005.

45. Lan F, Nottke AC and Shi Y: Mechanisms involved in the regulation of histone lysine demethylases. Curr Opin Cell Biol 20: 316-325, 2008.

46. Hayakawa T, Ohtani Y, Hayakawa N, Shinmyozu K, Saito M, Ishikawa F and Nakayama J: RBP2 is an MRG15 complex component and down regulates intragenic histoneH3 lysine 4 methylation. Genes Cells 12: 811-826, 2007.

47. Banck MS, Li S, Nishio H, Wang C, Beutler AS and Walsh MJ: The ZNF217 oncogene is a candidate organiser of repressive histone modifiers. Epigenetics 4: 100-106, 2009. 